\title{
Predictors of Knowledge and Attitude Regarding Organ Donation in Kuwait
}

\author{
Batool Y. Bosakhar, Zainab A. Al-Mesailekh, Shareefah A. Al-Farhan, Danah A. Arab, \\ Nour A. Al-Tawheid, Nourah F. Al-Ali, Amal K. Mitra \\ Department of Community Medicine and Behavioral Sciences, Faculty of Medicine, Kuwait University, \\ Kuwait.
}

\begin{abstract}
Background and objectives: In Kuwait, information regarding public knowledge and attitudes towards organ donation are scanty This study aimed to evaluate public knowledge and attitude regarding organ donation and determine factors which predict them.

Methods: This cross-sectional study was conducted among 630 participants recruited from 27 randomly selected public cooperative societies and private supermarkets in Kuwait. A self-administered questionnaire was used to collect data.

Results: The prevalence rate of knowledge about organ donation was $68 \%$, with a significantly higher rate among females than males $(73 \%$ vs. $63 \%$, respectively, $p=0.01)$. A composite score of knowledge was also higher among females than males $(8.4 \pm 5.8$ vs. $6.8 \pm 5.8$, respectively, $p=0.001)$. In multivariate analysis, female gender $(O R=1.7 ; 95 \% C I=1.2,2.4)$ and an educational level of bachelor's degree or higher $(O R=2.6,95 \% C I=1.7,3.9)$ were significant predictors of the knowledge. Among the barriers, more females than males mentioned about the fear of the operative procedures $(p<0.001)$ and complications after the surgery $(p=0.011)$. Overall, $73 \%$ accepted the idea of organ donation during life, and $67 \%$ actually opted for donating their organs during life. However, almost everybody wanted to donate organs to their relatives.
\end{abstract}

Conclusion: The study identified factors predicting knowledge and attitude regarding organ donation. The results will help in planning how to improve the rate of donors in Kuwait.

IMC J Med Sci 2016; 10(1): 01-09

\section{Introduction}

Many people around the world with end-stage organ failure are dying while on waiting lists for transplant surgery [1]. In 2012, 114,690 solid organs were reported to be transplanted globally, making a $1.8 \%$ increase over the year 2011. Still less than $10 \%$ of the global needs are met with the available donors. According to the Global Observatory on Donation and Transplantation (GODT), in 2012, the rate of organ donation in Spain was the highest worldwide, almost 35 deceased donors per one million, whereas, it was almost 26 deceased donors per one million persons in the United States, and 18 per one million in the United Kingdoms [2].

In Kuwait, the rate of organ donation is relatively low - only 6 deceased donors per one million persons, putting Kuwait well behind the US and Europe in this area. Between year 1996 and 2012 there were only 447 donations of kidneys, liver, pancreas, and heart [3]. A medical team in AlHamad Al-Essa Organ Transplant Center in Kuwait has performed 1,036 kidney transplant procedures from the period between November 1993 to December 2010, of which 278 were from brain death cases, 397 from relatives, and 361

Address for Correspondence:

Prof. Amal K. Mitra, Professor of Public Health, Department of Community Medicine and Behavioral Sciences, Faculty of Medicine, Kuwait University, Kuwait. E-mail: amalmitra16@yahoo.com 
from non-relative living donors. This makes the total number of kidney transplant procedures in Kuwait to be 1,596 procedures from the initiation of the program in Kuwait in February 1979 to January 2011 [3]. Still until October 2015, only 6,000 people in total in the country offering to donate their organs once they pass away through registration for organ donation card [4].

Several socio-cultural factors may influence attitudes of public towards organ donation. In a study conducted in late 2003 among Greater Detroit Arab Americans found Christian Arab Americans more likely than Muslim Arab Americans to believe organ donation after death being justifiable. Higher educational attainment and income, as well as greater acculturation into American society, were associated with greater odds of believing organ donation to be justified [5]. Regarding people's awareness about organ donation, a national study was conducted in China which showed that nearly $94 \%$ of the people in China were aware of organ donation. However, only $19 \%$ of this sample population actually carried organ donation cards [6].

In Saudi Arabia, shortage of organ donation remains a major limiting factor for transplantation [7]. To evaluate factors affecting the knowledge and/or attitudes towards organ donation, a cross-sectional study conducted in Saudi Arabia showed that about $40 \%$ of respondents accepted the concept of organ donation after their death, while $16 \%$ disagreed. When asked about possible reasons for organ donation refusal, $28 \%$ cited religious reasons and $23 \%$ did not want to have their bodies dissected after death [8]. Another study in Qatar revealed that about one-third of Qataris and more than onequarter of non-Qataris had no idea about the organ donation. The majority of the people in Qatar preferred donating organs to their close relatives and friends only [9].

Studies have suggested that knowledge and attitudes towards organ donation are influenced by factors such as gender, educational level, occupation, socio-demographic status, income level, culture, and religion [10]. Some of the barriers that may prevent people from donating organs include: fear of surgical and health risks, lack of knowledge, respect for cultural norms, financial loss, distrust in hospitals, and avoiding recipient indebtedness [11-12]. Studies have suggested that providing the general public by relevant information and correcting some of the misconceptions are likely to increase the number of individuals willing to donate organs [7].

In Kuwait, data regarding public knowledge and attitudes towards organ donation are scanty. Therefore, this study attempted to evaluate the knowledge and attitudes of people regarding organ donation.

\section{Methods \\ Study subjects}

The study was carried out among the general population in the city of Kuwait from December 2013 to January 2014. A list of 87 cooperative societies and private supermarkets were obtained from the Ministry of Commerce and Industry in Kuwait. Twenty-seven cooperative societies and private supermarkets were chosen by stratified random selection, using the administrative governorates as the strata. Cooperative Societies were chosen in the study for data collection since these are the main places where both expatriates and citizens from different socioeconomic backgrounds purchase their daily food supply and goods, making our sample most representative to the Kuwaiti population.

\section{Ethical approval}

The study was approved by the Ethics Committees at the Health Sciences Center of Kuwait University. The approvals were then obtained from the head of all cooperative societies and the manager of each private supermarket. An informed consent was obtained from the participants before enrollment.

\section{Data collection}

After reviewing published literature, a questionnaire was generated in both Arabic and English. The questionnaire consisting of 33 items was self-administered. Of them, 11 items assessed demographics, 12 items measured knowledge, and 10 items assessed attitude and willingness regarding organ donation. For each correct answer of the knowledge questions, a score of 1 was 
given. Regarding attitude, participants were asked if they are willing to donate, and if yes, which organs they are willing to donate and to whom (e.g. relative, friend, and/or anybody) during and/or after life. In addition, opinions about the barriers against organ donation and the best ways to promote organ donation were evaluated. The questionnaire was pre-tested among 20 persons recruited from the same population. Then modifications were made for clarity, simplicity and validity of the questionnaire. Two items were deleted for potential inconsistency in data.

A convenience sample, on first-come, first-serve basis, was obtained in two shifts, morning from 9 am to $12 \mathrm{pm}$, and evening from $4 \mathrm{pm}$ to $7 \mathrm{pm}$. The eligible participants were both females and males aged 18 years and above. People who could not read or write Arabic or English were excluded.

\section{Sample size estimation}

Based on the published reports from Gulf region [9], the proportion of people with lack of knowledge regarding organ donation was $30 \%$. In another study in China [6], $10 \%$ of the people had lack of knowledge about organ donation. In this study, the proportion of people with lack of knowledge about organ donation was considered to be not less than $10 \%\left(\mathrm{P}_{1}=0.10\right)$. To estimate the true proportion of the characteristics within $5 \%\left(\mathrm{P}_{2}\right.$ $=0.15)$, and the power of the study being $95 \%$, the required sample size was 562. Assuming a $10 \%$ dropout, the total sample size was 618 . The sample size was estimated using the G-power program.

\section{Statistical analysis}

Data analysis was done using SPSS for Windows software version 22 (SPSS Inc., Chicago, USA). Descriptive analysis was done to know the distribution of the data. For knowledge questions with known standard answers (e.g., organs to donate during life and after death) as obtained from the U.S Department of Health and Human Services (2013) [11], a scoring system was used by assigning one point for each correct answer. Mean values of knowledge scores were compared between people of either gender, nationality, marital status and education levels. Chi-square test was done for comparing categorical variables, and student $t$-test for continuous variables with normal distribution. Analysis of variance (ANOVA) was used to compare mean values of more than two groups. For data with non-normal distribution (e.g., knowledge scores), Mann Whitney U and Kruskal Wallis Test were used to compare mean values for two and more than two independent variables, respectively. A $p$-value of 0.05 was considered as statistically significant.

\section{Results}

\section{Demographics}

In total, 710 participants were handed out the questionnaire; $80(11 \%)$ were dropped from this analysis due to missing data for major variables. However, those who dropped out did not differ from those who were remained in terms of demographic variables. Of the remaining 630 participants, $51.2 \%$ were females and $47.9 \%$ were males. Mean age $(S D)$ of the participants was 33.4 (11.5) years, ranging from 18 to 76 years. Kuwaitis represented majority $(66 \%)$ of the study population.

Table-1: Knowledge about organ donation and sources of information

\begin{tabular}{lcc}
\hline Variable & No. & \% \\
\hline Knew about organ donation & $430 / 630$ & 68.3 \\
Sources of Information & & \\
$\quad$ Radio/TV/Internet & $354 / 439$ & 80.6 \\
$\quad$ Newspapers/Magazines & $233 / 438$ & 53.2 \\
$\quad$ Posters/Public health campaigns & $114 / 438$ & 26.0 \\
Health providers & $106 / 437$ & 24.3 \\
Family and friends & $175 / 437$ & 40.0 \\
$\quad$ School & $10 / 136$ & 7.4 \\
Knew about any organ donation & $90 / 436$ & 20.6 \\
association or society in Kuwait & & \\
Heard about an organ donation card & $121 / 436$ & 27.7 \\
When can a person donate organs & & \\
$\quad$ During life only & $45 / 436$ & 10.3 \\
$\quad$ After death only & $81 / 436$ & 18.6 \\
$\quad$ Both & $310 / 436$ & 71.1 \\
\hline
\end{tabular}

\section{Knowledge about Organ Donation}

Table 1 shows that $68.3 \%(430 / 630)$ of the respondents knew about organ donation. Of those who knew about organ donation, $80.6 \%$ heard it from radio/television/internet as being their 
04 IMC J Med Sci 2016; 10(1): 01-09

Bosakhar BY et al.

Table-2: Comparison of knowledge about organ donation by gender

\begin{tabular}{|c|c|c|c|c|}
\hline Variable & $\begin{array}{c}\text { Male } \\
n=302\end{array}$ & $\begin{array}{c}\text { Female } \\
n=328\end{array}$ & $\begin{array}{c}P \text { - } \\
\text { value }\end{array}$ & $\begin{array}{c}\text { All } \\
n=630\end{array}$ \\
\hline Know about organ donation (\%) & $191(63.2)$ & $239(72.9)$ & $0.01^{\mathrm{a}}$ & $430(68.3)$ \\
\hline When can a person donate an organ & & & $0.62^{\mathrm{a}}$ & \\
\hline During life & 21/192 (10.9) & $24 / 244(9.8)$ & & $45 / 436(10.3)$ \\
\hline After death & $39 / 192(20.3)$ & $42 / 244(17.2)$ & & $81 / 436(18.6)$ \\
\hline Both & $132 / 192(68.8)$ & $178 / 244(73.0)$ & & $310 / 436(71.1)$ \\
\hline Knowledge score & & & & \\
\hline $\begin{array}{l}\text { What organs a person can donate } \\
\text { during life (out of } 8 \text { ) }\end{array}$ & $2.29 \pm 2.08$ & $2.79 \pm 2.09$ & $0.003^{\mathrm{b}}$ & $2.55 \pm 2.10$ \\
\hline $\begin{array}{l}\text { What organs a person can donate } \\
\text { after death (out of } 8 \text { ) }\end{array}$ & $2.70 \pm 2.84$ & $3.40 \pm 2.80$ & $0.002^{\mathrm{b}}$ & $3.07 \pm 2.84$ \\
\hline Who can donate an organ (out of 4 ) & $1.84 \pm 1.59$ & $2.17 \pm 1.56$ & $0.007^{\mathrm{b}}$ & $2.01 \pm 1.58$ \\
\hline Total score (out of 20) & $6.83 \pm 5.83$ & $8.36 \pm 5.82$ & $0.001^{\mathrm{b}}$ & $7.63 \pm 5.87$ \\
\hline
\end{tabular}

${ }^{a}$ Chi-Square Test; ${ }^{b}$ Mann-Whitney U Tes

primary source of information, and $53.2 \%$ chose newspapers and magazines as their source of information. Only $27.7 \%$ of the respondents heard about organ donation card. A vast majority (71.1\%) agreed that organ donation is possible in both during life and after death.

When participants' knowledge regarding the organs that can be donated during life was assessed, kidney $(93.4 \%)$, part of liver $(55.9 \%)$ and bone marrow $(37.6 \%)$ were chosen as possible organs, while after death, kidneys $(71.8 \%)$, liver $(68.2 \%)$, heart $(76.4 \%)$ and bone marrow $(43.8 \%)$ were chosen as major organs.

Table 2 compares the participants' knowledge about organ donation by gender. A significantly higher proportion of females than males $(72.9 \%$ vs. $63.2 \%$, respectively; $p=0.01$ ) knew about organ donation. When knowledge scores were compared by gender, more females than their male counterparts had a higher score in terms of specific knowledge about what organs a person can donate during life $(p=0.003)$ or after death $(p=0.002)$, and who can donate any organs $(p=0.007)$.

\section{Relation between Formal Education and Knowledge}

In terms of education, mean knowledge scores of organ donation increased linearly with higher levels of education (Figure 1). The people with a post-high school diploma showed a higher mean knowledgeable score about organ donation when compared with those with a high-school or less education, although data were not significant.
Similarly, those who have had a bachelor degree or higher education showed a statistically significant higher knowledge score for organ donation compared to those who have had less than a bachelor degree education $(p<0.001)$.

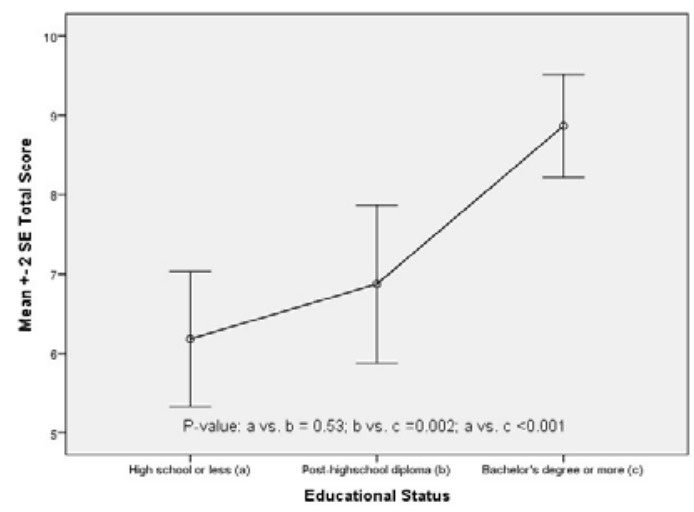

Fig.1: Knowledge scores for organ dontion by educational status of participants. Participants with bachelor's degree or higher educational status had significantly more knowledge scores compared to the other levels of education

Multivariate Analysis to Predict Knowledge about Organ Donation

In logistic regression analysis (Table 3), female gender $(O R=1.7 ; 95 \% C I=1.2,2.4)$, and an educational level of bachelor's degree or higher $(O R=2.6,95 \% C I=1.7,3.9)$ were significant predictors of those who had knowledge about organ donation. Those variables were selected 
Table-3: Logistic regression analysis to predict knowledge about organ donation

\begin{tabular}{|c|c|c|c|}
\hline Variable & $\begin{array}{l}\text { Odds } \\
\text { ratio }\end{array}$ & $\begin{array}{c}95 \% \\
\text { Confidence } \\
\text { Intervals } \\
\end{array}$ & $\begin{array}{c}P- \\
\text { value }\end{array}$ \\
\hline Age group & & & \\
\hline $18-25 y$ & \multicolumn{3}{|c|}{ Reference } \\
\hline $26-45$ y & 1.03 & $0.62,1.72$ & 0.91 \\
\hline$\geq 46 y$ & 1.98 & $0.97,4.01$ & 0.06 \\
\hline \multicolumn{4}{|l|}{ Gender } \\
\hline \multicolumn{4}{|l|}{ Nationality } \\
\hline Kuwaiti & \multicolumn{3}{|c|}{ Reference } \\
\hline $\begin{array}{l}\text { Non-Kuwaiti } \\
\text { Marital status }\end{array}$ & 1.38 & $0.94,2.04$ & 0.11 \\
\hline Single & \multicolumn{3}{|c|}{ Reference } \\
\hline Married & 1.39 & $0.86,2.24$ & 0.18 \\
\hline $\begin{array}{l}\text { Widowed or } \\
\text { Divorced }\end{array}$ & 3.58 & $1.09,11.80$ & 0.036 \\
\hline $\begin{array}{l}\text { Education level } \\
\text { High school or less }\end{array}$ & Referes & & \\
\hline $\begin{array}{l}\text { Post high school } \\
\text { diploma }\end{array}$ & 1.50 & $0.94,2.40$ & 0.09 \\
\hline $\begin{array}{l}\text { Bachelor's degree } \\
\text { or higher }\end{array}$ & 2.59 & $1.72,3.89$ & $<0.001$ \\
\hline
\end{tabular}

based on significant associations observed in univariate analysis. The variables which were controlled for included location of residence (governorate), nationality, religion, family income, parents' education, and occupation.
Attitudes about Organ Donation by Gender

Table 4 shows that about $73 \%$ of the study participants opined favorably for organ donation during life. When asked if they are willing to donate his/her organs during life, $67 \%$ responded positively. A vast majority of them $(98 \%)$ were willing to donate an organ for their family members, whereas $68 \%$ mentioned it for their friends, and only $37 \%$ mentioned that they would donate it for anybody. No differences were observed in the attitudes towards organ donation by gender.

When asked about the perceived barriers of organ donation, the majority mentioned about family objection $(60 \%)$, lack of knowledge $(72 \%)$, and fear of the operative procedures (76\%). A significantly higher proportion of females than males $(83 \%$ vs $69 \%$, respectively; $p<0.001)$ mentioned about the later as the most common barrier of organ donation. In addition, more females than males also mentioned about health complications following organ donation as another possible barrier of organ donation (77\% vs. $67 \%$, respectively; $p=0.011$ ).

When asked about the people's opinion on what should be done to increase the number of organ donors in the country, the major suggestions included enhancing public awareness through organized public health campaigns (89\%), providing more information on health risks and safety of organ donation $(87 \%)$, and incorporating

Table-4: Comparison of attitudes about organ donation by gender

\begin{tabular}{lcccc}
\hline \multicolumn{1}{c}{ Variable } & $\begin{array}{c}\text { Male } \\
\boldsymbol{n}=\mathbf{3 0 2}\end{array}$ & $\begin{array}{c}\text { Female } \\
\boldsymbol{n}=\mathbf{3 2 8}\end{array}$ & $\begin{array}{c}\boldsymbol{P} \text { - } \\
\text { value }^{\mathrm{a}}\end{array}$ & $\begin{array}{c}\text { All } \\
\boldsymbol{n}=\mathbf{6 3 0}\end{array}$ \\
\hline $\begin{array}{l}\text { Do you accept the idea of organ donation during life } \\
\text { Are you willing to donate your organs during life }\end{array}$ & $216 / 301(71.8)$ & $244 / 327(74.6)$ & 0.24 & $460 / 628(73.2)$ \\
To whom are you willing to donate an organ & $153 / 222(68.9)$ & $163 / 248(65.7)$ & 0.76 & $316 / 470(67.2)$ \\
$\quad$ & & & \\
$\quad$ Family members & $91 / 91(100.0)$ & $127 / 132(96.2)$ & 0.17 & $218 / 223(97.8)$ \\
$\quad$ Friends & $65 / 91(71.4)$ & $85 / 131(64.9)$ & 0.055 & $150 / 222(67.6)$ \\
$\quad$ Anybody & $28 / 89(31.5)$ & $53 / 131(40.5)$ & 0.18 & $81 / 220(36.8)$ \\
What prevents people from donating organs & & & & \\
$\quad$ Family objection & $168 / 299(56.2)$ & $209 / 326(64.1)$ & 0.12 & $377 / 625(60.3)$ \\
$\quad$ No financial benefits & $63 / 299(21.1)$ & $62 / 324(19.1)$ & 0.83 & $125 / 623(20.1)$ \\
$\quad$ Religious barrier & $132 / 300(44.0)$ & $116 / 325(35.7)$ & 0.10 & $248 / 625(39.7)$ \\
$\quad$ Lack of knowledge & $194 / 301(64.5)$ & $226 / 327(69.1)$ & 0.46 & $420 / 628(66.9)$ \\
$\quad$ Health complications & $199 / 298(66.8)$ & $253 / 328(77.1)$ & 0.011 & $452 / 626(72.2)$ \\
Fear of the operation itself & $207 / 301(68.8)$ & $271 / 328(82.6)$ & $<0.001$ & $478 / 629(76.0)$ \\
\hline
\end{tabular}

${ }^{\mathrm{a} C h i-S q u a r e ~ T e s t ~}$ 
organ donation information in school and university curriculum (73\%).

\section{Discussion}

In this study, females had a significantly higher knowledge about organ donation. The composite score of knowledge also outnumbered in females than their male counterparts. This gender difference in knowledge persisted even after multivariate analysis. However, attitudes toward organ donation did not differ by gender. Among the perceived barriers, females had significantly greater fear of the operative procedures and complications after the surgery compared to males.

A higher knowledge of organ donation in females in Kuwaiti general population is a unique finding. This probably can be attributable to an overall higher level of education in females in Kuwait. As demonstrated in the UNESCO report, the gross enrolment ratios in the tertiary level of education is higher among women than men in Kuwait (29\% vs. $15 \%$ ) [13]. In our study, the proportion of females with a bachelor degree or higher was slightly higher than that of males $(49.4 \%$ vs. $47.0 \%$, respectively), although the data were not statistically significant.

The gender differences regarding the knowledge and willingness towards organ donation have been studied in a lot of literature over the years. In the U.S., 1988, the female-to-male organ donation was 1.2 (55\% female vs. $45 \%$ male donors), and it has since then increased to 1.4 in 1998 (58\% female vs. $42 \%$ male donors) [14]. These results correspond with the data above in our study. Several factors are thought to lead to such unbalanced ratio between the two genders. First, and perhaps the most important, is that female donors are more empathetic and altruistic, and they use this empathy and the desire to help others as their motivation for donation. Also, women are more likely to donate than men since they perceive themselves are the primary caregivers in the society [15].

After adjusting for demographic variables such as location of residence, nationality, religion, parent's level of education, family income, and occupation, respondent's education level remained as an independent significant predictor of knowledge about organ donation. A similar association between level of education and knowledge about organ donation was observed in a study in Brazil [16]. In Seattle, Washington, a classroom education session among school-age children significantly improved the knowledge scores $(p<$ 0.001 ), as well as their willingness in donating organs $(p<0.0001)$, irrespective of their ethnicity and gender [17], although both female gender and education were independent predictors of knowledge in our study.

The prevalence of knowledge regarding organ donation in our study $(68 \%)$ was similar to that in Qatar. However, in the study in Qatar there was no significant gender difference in knowledge about organ donation [9]. In Saudi Arabia, a much higher rate (more than $90 \%$ ) of knowledge about organ donation and transplantation was observed compared to that in our study. This difference might be due to a combination of higher educational level and public awareness among the participants in Saudi Arabia compared to those of our participants [18]. Similarly, the rate of knowledge about organ donation was also much higher $(89 \%)$ in a study conducted among South African adults [19]. This difference in knowledge could easily be accounted for the ethnic background of the people. However, the study conducted in South Africa only included participants from metropolitan areas, characterized by close proximity to major cities, and those being wealthier. The study in South Africa excluded the rural areas, while our study was designed to include a representative sample of people from all the governorates in Kuwait.

In our study, the major sources of knowledge of the people were radio, television, and the internet $(81 \%)$, followed by newspapers or magazines $(53 \%)$. This is in conformity with another crosssectional study conducted in Saudi Arabia where $90 \%$ of people in both rural and urban areas stated that television was their main source of information about organ donation, and that health providers provided little or no knowledge about organ donation [7]. Similarly, television viewing (48\%) was primarily cited as the source of knowledge, followed by the word of mouth, and magazines and newspapers in the study conducted in South Africa 
[19]. In a community of southwestern Ontario, $90 \%$ of the respondents cited newspapers or magazines and televisions as their primary sources of information about organ transplantation [20]. A recent study in Venezuela demonstrated that positive media campaign can have a significant impact on organ donation rates [21]. All these studies supported the role of mass media and social media in increasing awareness and the levels of knowledge regarding organ donation worldwide.

In our study, when subjects' knowledge regarding organs that can be donated during life was assessed, kidney (93\%), part of liver (56\%) and bone marrow (38\%) were chosen as possible organs, while kidney (72\%), liver $(68 \%)$, heart (76\%) and bone marrow (44\%) were chosen as possible organs for donation after death. In a crosssectional study in Brazil, the organs mentioned more often for transplant included kidney (89\%), heart $(75 \%)$, liver $(60 \%)$, cornea $(58 \%)$, and bone marrow (26\%) [14]. It is possible that people mentioned kidney most often for donation because of more media campaign for kidney in Kuwait. Shortage of many other organs is similarly high and causes many deaths without receiving organs. Studies recommend that media take a proactive role in disseminating the acute need of donors for many other organs too.

People sometimes believe living donor transplantation as a potential risk for surgical complications, physical harm, and death of the donor. However, in the United States, the donor mortality rate due to surgical complications was only $0.03 \%$ [11]. We assessed what participants believed as a barrier for organ donation. Among the perceived barriers, the fear of the operation itself $(76 \%)$, health complications $(72 \%)$ and lack of knowledge (67\%) were mentioned more frequently in our study, which were consistent with the study in Qatar [9]. It has long been known that rate of organ donation is low among Muslims in North America [19]. In the past this low rate has been attributed to religious prohibitions even though cultural views may also play a strong role $[16,22]$. Interestingly, religious cause was not mentioned as a significant barrier when the people were compared by gender, education, or marital status in our study. According to the Islamic council in Saudi Arabia, the "Senior Ulama
Commission", it is permitted to donate and transplant tissue and organs from both living and cadaveric donors. Because there are differences in perceived barriers in studies across the world, public education strategies for improving organ donation and transplantation should be developed targeting the specific population.

In our study, when people were asked about their suggestions to improve the number of organ donors, more than $80 \%$ suggested enhancing the public health campaigns, and providing more information on health risks and safety of organ donation, and more than $70 \%$ suggested inclusion of organ donation information in school and university curriculum. In Turkey, people opined that information disseminated through booklets may increase the number of donors, whereas in South Africa, recommendations included to educate the society about organ donation by simple educational and advertising campaigns [23]. Also, the more sessions the campaign consisted of, the higher the signature rates. This was shown by a campaign done among university students of Louisville, U.S that consisted of two sessions, allowing more time for the mental preparation to decide either to sign the card or not [24]. Moreover, a one-on-one interventions promotion campaign that was done in Sweden, reported a positive change in willingness before and after the interview [25]. Because of the impact of public awareness interventions on living donation rates, we recommend mass organ donation campaigns to improve the situation in Kuwait. Additionally, we may adopt the success strategies of some other countries, which include paired kidney exchange, altruistic non-directed donation programs (a form of donation whereby a healthy living person donates a kidney to an unknown recipient), and the presence of full-time transplantation coordinators responsible for the entire donation process in large hospitals $[11,26]$. One successful example of an organ procurement center in an Islamic country is the Saudi Center for Organ Transplantation (SCOT). SCOT has attempted to improve the awareness of the medical community to the importance of organ donation and transplantation by adopting several tools: training courses, visits to donating hospitals, conferences, publication (journals, booklets, pamphlets, posters, and books), curricula of medical schools, and curricula 
of postgraduate hospital training. Furthermore, SCOT succeeded in adopting tools to improve the awareness the public at large to improve organ donation and transplantation, which include education (e.g. exchange visits with schools, public debates and meetings), media (e.g. television, lay press, booklets, pamphlets), donation cards, and public surveys of approval for organ donation [27].

One of the limitations of our study was that this was a cross-sectional study which cannot establish a causal relationship. Although data of 80 people (11\%) were incomplete and could not be analyzed, the relatively large sample size using a multistage random selection procedure could probably nullify the effect of bias and the study results may represent the entire population of Kuwait. Moreover, this was the only study, to our knowledge, conducted among the general population in Kuwait regarding public knowledge towards organ donation.

\section{Conclusion}

In conclusion, our study identified female gender and education as independent significant predictors of knowledge regarding organ donation. Thus, an adequate educational programmers, mass campaigns, and organ procurement system should be adopted to increase awareness of general population about the importance of organ donation; hence increasing the rate of donation.

\section{Acknowledgment}

The authors are thankful to Dr. Maqsood Nazar for his technical assistance, and to Dr. Reem Al-Sabah for her suggestions in the Arabic translation of the questionnaire.

\section{References}

1. Marck CH, Weiland TJ, Neate SL, Hickey BB, Jelinek GA. Personal attitudes and beliefs regarding organ and tissue donation: a crosssectional survey of Australian emergency department clinicians. Prog Transplant 2012; 22(3): 317-322.
2. Global Observatory on Donation and Transplantation, GODT: Organ Donation and Transplantation Activities, 2012. Available at http://www.transplant-observatory.org/Pages/Facts.aspx, accessed on October 10, 2015.

3. Kuwait Transplant Society: Kuwait transplant statistics. Available at http://transplant.org.kw, accessed on May 8, 2015.

4. International Association of Living Organ Donors: Culture limits lifesaving organ donor numbers, 2011. Available at http://livingdonorsonline. org/ldosmf/index. php?topic $=1042.0$, accessed on October 8, 2015.

5. Padela AI, Rasheed S, Warren GJW, Choi H, Mathur AK. Factors associated with positive attitudes toward organ donation in Arab Americans. Clin Transplant 2011; 25(5): 800808.

6. Manninen DL, Evans RW. Public attitudes and behavior regarding organ donation. JAMA 1985; 253(21): 3111-3115.

7. Alghanim SA. Knowledge and attitudes toward organ donation: a community-based study comparing rural and urban populations. Saudi J Kidney Dis Transpl 2010; 21(1): 23-30.

8. Alam AA. Public opinion on organ donation in Saudi Arabia. Saudi J Kidney Dis Transpl 2007; 18: 54-59.

9. El Shoubaki H, Bener A, Al Mosalamani Y. Factors influencing organ donation and transplantation in State of Qatar. Transplantationsmedizin 2006; 18(S): 97-103.

10. El Shoubaki H, Bener A. Public knowledge and attitudes toward organ donation and transplantation: a cross-cultural study. Transplant Proc 2005; 37(5): 1993-1997.

11. Tong A, Chapman JR, Wong G, Josephson MA, Craig JC. Public awareness and attitudes to living organ donation: systematic review and integrative synthesis. Transplantation 2013; 96(5): 429-437.

12. U.S. Department of Health \& Human Services. About donation and transplantation. Available athttp://organdonor.gov/about/livedonation.html, accessed on May 8, 2015. 
13. UNICEF. Kuwait. MENA gender equality profile: Status of girls and women in the Middle East and North Africa. 2011.

14. United Network for Organ Sharing: 1999b, Number of Living Donors: January 1988-June 30, 1999. Richmond, VA: UNOS OPTN/ Scientific Registry.

15. Switzer GE, Dew MA, Butterworth VA, Simmons RG, Schimmel M. Understanding Donors' Motivations: A Study of Unrelated Bone Marrow Donors. Social Science and Medicine 1997; 45(1): 137-147.

16. Sasso-Mendes KD, Curvo PA, Silveira RC, Galvão CM. Organ donation: acceptance and refusal among users of the public health system from Brazil. Transplant Proc 2008; 40(3): 660-662.

17. Cardenas V, Thornton JD, Wong KA, Spigner C, Allen MD. Effects of classroom education on knowledge and attitudes regarding organ donation in ethnically diverse urban high schools. Clin Transplant 2010; 24(6): 784-793.

18. Mohamed E, Guella A. Public awarness survey about organ donation and transplantation. Transplant Proc 2013; 45(10): 3469-3471.

19. Etheredge HR, Turner RE, Kahn D. Public attitudes to organ donation among a sample of urban-dwelling South African adults: a 2012 study. Clin Transplant 2012; 27(5): 684-692.
Evers S, Farewell VT, Halloran PF. Public awareness of organ donation. Canadian Med Assoc J 1988; 138(3): 237-239.

21. Coad L, Carter N, Ling J. Attitudes of young adults from the UK towards organ donation and transplantation. Transplant Res 2013; 2: 2-9.

22. Syed J. Islamic views on organ donation. $J$ Transpl Coord 1998; 8(3): 157-160.

23. Ozdag N. Public awarness and acceptance of tissue and organ donation. EDTNA-ERCA Journal 2004; 30: 188-195.

24. Birkimer JC, Barbee AP, Francis ML, Berry MM, Deuser PS, Pope JR. Effects of refutational messages, thought provocation, and decision deadlines on signing to donate organs. Journal of Applied Social Psychology 1994; 24(19): 1735-1761.

25. Sanner MA, Hedman H, Tufveson G. Evaluation of an organ-donor-card campaign in Sweden. Clin Transplant 1995; 9(4): 326333.

26. Schauenburg H, Hildebrandt A. Public knowledge and attitudes on organ donation do not differ in Germany and Spain. Transplant Proc 2006; 38(5): 1218-1220.

27. Shaheen FA, Souqiyyeh MZ. Increasing organ donation rates from muslims donors: lessons from a successful model. Transplant Proc 2004; 36(7): 1878-80.

20. 